\title{
Isoliquiritigenin inhibits the survival of diffuse large B-cell lymphoma cells by regulating Akt/mTOR signaling pathway
}

\author{
Zhixiang Su${ }^{1}$, Bin $\mathrm{Yu}^{2 *}$, Zhiping Deng ${ }^{3}$, Haifeng Sun ${ }^{1}$ \\ ${ }^{1}$ Department of Medical Oncology Hospital Unit 3, ${ }^{2}$ Department of Medical Oncology Hospital Unit Chinese Integrative, \\ ${ }^{3}$ Department of Mastosis Hospital, Shaanxi Province Cancer Hospital, Xi'an City, Shaanxi Province 710061, China \\ *For correspondence: Email: AZXS073@163.com; Tel: +86-29-85276130
}

\begin{abstract}
Purpose: To investigate the effect of isoliquiritigenin (ISL) on diffuse large B-cell lymphoma (DLBCL) cells and its underlying mechanism of action.

Methods: The DLBCL cell line OCI-Ly19 was used in this study. Cell proliferation was measured by MTT assay. Apoptosis was evaluated using flow cytometry. Phosphorylation of Akt and mTOR was assessed using Western blotting.

Results: DLBCL cell proliferation was suppressed by ISL in a concentration-dependent manner. The number of apoptotic cells increased following ISL treatment in a concentration-dependent manner ( $p<$ 0.05). ISL treatment also stopped the cell cycle at the G1 phase in a concentration-dependent manner. Western blot analysis indicated that there was no significant Akt and mTOR expression in cells treated with 10, 20, or $50 \mu \mathrm{M}$ ISL $(p<0.05)$. However, Akt and mTOR phosphorylation was upregulated following treatment with 10, 20, or $50 \mu \mathrm{M}$ ISL in a concentration-dependent manner $(p<0.05)$.

Conclusion: The results demonstrate that ISL inhibits DLBCL cell proliferation and promotes cell apoptosis by blocking the cell cycle transition from the $\mathrm{G} 1$ to $S$ phase, which is mediated by the inactivation of the Akt/mTOR signaling pathway.
\end{abstract}

Keywords: Isoliquiritigenin, Cell survival, Diffuse large B-cell lymphoma, Akt/mTOR signaling pathway

This is an Open Access article that uses a fund-ing model which does not charge readers or their institutions for access and distributed under the terms of the Creative Commons Attribution License (http://creativecommons.org/licenses/by/4.0) and the Budapest Open Access Initiative (http://www.budapestopenaccessinitiative.org/read), which permit unrestricted use, distribution, and reproduction in any medium, provided the original work is properly credited.

Tropical Journal of Pharmaceutical Research is indexed by Science Citation Index (SciSearch), Scopus, International Pharmaceutical Abstract, Chemical Abstracts, Embase, Index Copernicus, EBSCO, African Index Medicus, JournalSeek, Journal Citation Reports/Science Edition, Directory of Open Access Journals (DOAJ), African Journal Online, Bioline International, Open-J-Gate and Pharmacy Abstracts

\section{INTRODUCTION}

Diffuse large B-cell lymphoma (DLBCL) is the most common among lymphoid neoplasms and accounts for $30 \%$ of non-Hodgkin lymphomas in adults [1]. DLBCL is defined as a malignancy with a diffuse pattern of large B-cells [2]. The prognosis of DLBCL is diverse due to its clinical, pathological, and molecular heterogeneity [3]. The standard therapeutic regimen for DLBCL has remained largely unchanged for over 25 years, with cyclophosphamide, doxorubicin, vincristine, and prednisone (CHOP) chemotherapy still in use [4]. With the addition of rituximab $(R)$ to $\mathrm{CHOP}$, the 6-year event-free survival has increased from $55.8 \%$ to $74.3 \%$, greatly improving the long-term prognosis for young patients with DLBCL [5]. However, the 5-year event-free survival was only $47 \%$ in elderly patients with DLBCL [6]. Thus, a new therapeutic strategy is required to further extend the longterm survival of DLBCL patients. 
Many studies have concluded that the phosphoinositide 3-kinase (PI3K)/protein kinase $\mathrm{B}$ (Akt)/mammalian target of rapamycin (mTOR) signaling pathway is activated in the pathogenesis of cancers, including endometrial cancer, breast cancer, and DLBCL [7]. PI3K interacts with phosphorylated tyrosine on IRS molecules, resulting in further phosphorylation and activation of Akt [8]. Phosphorylation of Akt activates mTOR, a downstream serine/threonine kinase of the PI3K/Akt/mTOR pathway, leading to the upregulation of mRNA translation, protein synthesis, and cell proliferation $[9,10]$. Therefore, inhibition of the PI3K/Akt/mTOR pathway is a potential therapeutic target for DLBCL.

Isoliquiritigenin (ISL, 2',4',4-trihydroxychalcone, Figure $1 \mathrm{~A}$ ) is a bioactive chalcone compound isolated from licorice root (Mongolian glycyrrhiza, Glycyrrhiza glabra, and Glycyrrhiza uralensis) [11]. ISL has multiple documented pharmacological activities, including antiinflammation, anti-angiogenesis, and anti-cancer [12]. ISL treatment reduces sepsis-induced liver and lung injury via inhibition of the NF-kB signaling pathway in a mouse model [13]. In human prostate cancer, ISL promotes cell apoptosis and induces cell cycle arrest at the G2/M phase by modulating the cyclin B1-CDK1 complex [14]. In lung cancer cells, ISL suppressed proliferation and migration by inactivating the PI3K/Akt pathway [15]. However, there are no reports on the effects of ISL on DLBCL. The objective of this study was to explore the effects of ISL on DLBCL cells and to define its underlying mechanism.

\section{EXPERIMENTAL}

\section{Cell culture and treatment}

The DLBCL cell line OCI-Ly19 was obtained from the American Type Culture Collection (ATCC, USA). OCl-Ly19 cells were grown in RPMI-1640 (Thermo Fisher, USA) containing $10 \%$ fetal bovine serum (FBS, Thermo Fisher) and 1\% penicillin-streptomycin solution (Thermo Fisher) at $5 \% \mathrm{CO}_{2}$ at $37^{\circ} \mathrm{C}$. ISL (Sigma-Aldrich, USA) was dissolved in methanol (Sigma-Aldrich) at a concentration of $1 \mathrm{mM}$. OCl-Ly19 cells were cultured in sterile 12-well plates at a density of 1 $\times 10^{5}$ cells/well and treated with 10,20 , or $50 \mu \mathrm{M}$ ISL for 24 hours. After treatment, cells were collected for further analysis.

\section{MTT assay}

After treatment with ISL for 24 hours as described above, OCI-Ly19 cells were collected and centrifuged. Cell pellets were rinsed with phosphate buffer saline (PBS) and incubated with $20 \mu \mathrm{l}$ of MTT solution at $37^{\circ} \mathrm{C}$ for 4 hours. Precipitated formazan was dissolved in $150 \mu \mathrm{L}$ DMSO. The absorbance at $490 \mathrm{~nm}$ was measured using a spectrophotometer (BioTek, USA).

\section{Flow cytometry}

After ISL treatment, OCI-Ly19 cells were washed with PBS and resuspended at $1 \times 10^{7}$ cells $/ \mathrm{mL}$. Cell suspensions were stained with Annexin-VFITC and PI (Sigma-Aldrich) for 15 minutes. Apoptosis was analyzed on a FACS Calibur flow cytometer (Becton Dickenson, USA). Data was collected from 20,000 cells per sample and presented as two-parameter dot-plots.

\section{Western blotting}

Protein was extracted using RIPA cell lysis buffer (Beyotime, China) and $5 \mu \mathrm{g}$ of protein was loaded onto $7.5 \%$ polyacrylamide gels (SDSPAGE) and separated by electrophoresis. Separated proteins were transferred to PVDF membranes. Membranes were blocked with $5 \%$ BCA buffer for $1 \mathrm{~h}$ at room temperature and then probed with primary antibodies overnight at $4{ }^{\circ} \mathrm{C}$. The primary antibodies used in this study were: p-Akt (CST\#9271, 1:1000 dilution), Akt (CST\#2920, 1:2000 dilution), p-mTOR (CST\#5536, 1:500 dilution), mTOR (CST\#2983, 1:500 dilution), and GAPDH (CST\#5174, 1:5000 dilution). Membranes were incubated with appropriate secondary antibodies, followed by protein detection using ECL Detection reagents (Sigma-Aldrich). Protein bands were analyzed using Image Lab 3.0 (Bio-Rad, USA).

\section{Statistical analysis}

Data were statistically analyzed using SPSS 17.0 software (IBM, USA) and are presented as mean $\pm \operatorname{SEM}(\mathrm{n}=3)$. Comparisons between two groups were performed using Student's $t$ tests. Comparisons among multiple groups were determined using one-way ANOVA. $P<0.05$ was taken to indicate statistically significant differences.

\section{RESULTS}

\section{ISL inhibited cell proliferation in DLBCL cells}

Results from the MTT assays showed that cell viability was significantly reduced in OCl-Ly19 cells treated with 10,20 , or $50 \mu \mathrm{M}$ ISL compared with untreated cells (Figure $1 \mathrm{~B}$ ). The inhibition of cell proliferation by ISL was in a concentrationdependent manner (Figure 1). 
<smiles>O=C(/C=C/c1ccc(O)cc1)c1ccc(O)cc1O</smiles>

B

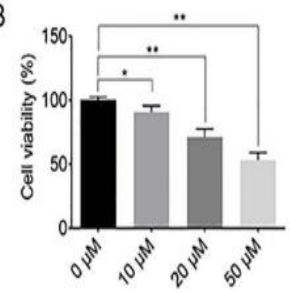

Figure 1: ISL inhibited cell proliferation in DLBCL cells. (A) Chemical structure of ISL. (B) Cell viability was reduced following ISL treatment for 24 hours in a concentration-dependent manner; ${ }^{* *} p<0.01$ compared to $0 \mu \mathrm{M}$. ISL: isoliquiritigenin; $0 \mu \mathrm{M}: 0 \mu \mathrm{M}$ of ISL

\section{ISL blocked cell cycle progression from $\mathrm{G} 1$ to S phase}

After treatment with ISL, the number of OCl-Ly19 cells in the $\mathrm{G} 1$ phase was significantly increased in a concentration-dependent (Figure 2). The number of OCl-Ly19 cells in the S phase was significantly reduced following treatment with 10 , 20 , or $50 \mu \mathrm{M} I S L$ in a concentration-dependent manner (Figure 2). The number of OCl-Ly19 cells in the G2 phase did not show any significant changes following treatment with 10,20 , or 50 $\mu \mathrm{M}$ ISL compared with the control group (Figure 2).

\section{ISL promoted apoptosis in DLBCL cells}

Apoptosis was measured using flow cytometry. Data in two-parameter dot-plots demonstrated that the percent of double-positive (dead) cells in the second quadrant was $3.63,7.29,10.1$, and $18.3 \%$ in cells treated with $0,10,20$, and $50 \mu \mathrm{M}$ ISL, respectively (Figure 3 ). The percent of cells undergoing apoptosis (Annexin-V-positive, third quadrant) was $1.98,3.61,3.45$, and $3.94 \%$ in cells treated with $0,10,20$, and $50 \mu \mathrm{M}$ ISL, respectively (Figure 3 ). Statistical analysis indicates that the number of apoptotic cells increased following treatment with 10,20 , and 50 $\mu \mathrm{M}$ in a concentration-dependent manner (Figure $3)$.

\section{ISL repressed the activation of the Akt/mTOR signaling pathway}

Western blot results indicated that there was no significant difference in Akt and mTOR expression in cells treated with $0,10,20$, and 50 $\mu \mathrm{M}$ of ISL (Figure 4). However, the phosphorylation of Akt was upregulated following 10,20 , and $50 \mu \mathrm{M}$ ISL in a concentrationdependent manner (Figure 4). The phosphorylation of mTOR was also upregulated following 10, 20, and $50 \mu \mathrm{M}$ ISL in a concentration-dependent manner (Figure 4).
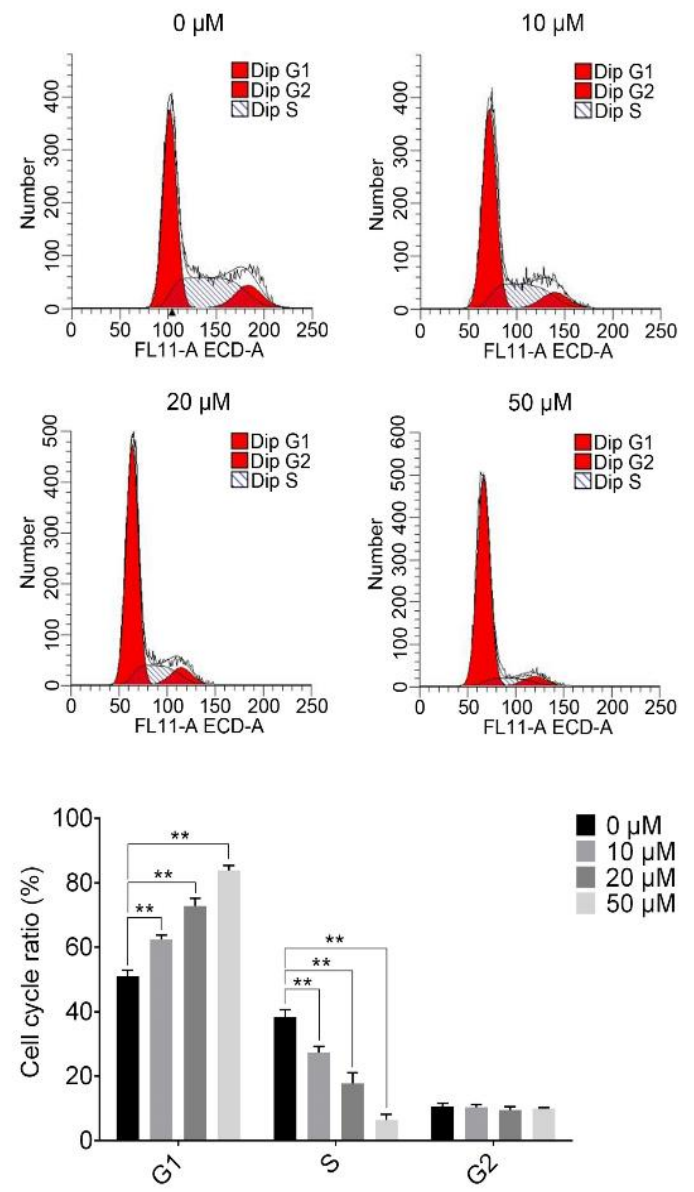

Figure 2: ISL treatment for 24 hours blocked cell cycle progression from $\mathrm{G} 1$ to $\mathrm{S}$ phase. Cell cycle was arrested at G1 phase by ISL in a concentrationdependent manner; ${ }^{* *} p<0.01$ vs. $0 \mu \mathrm{M}$
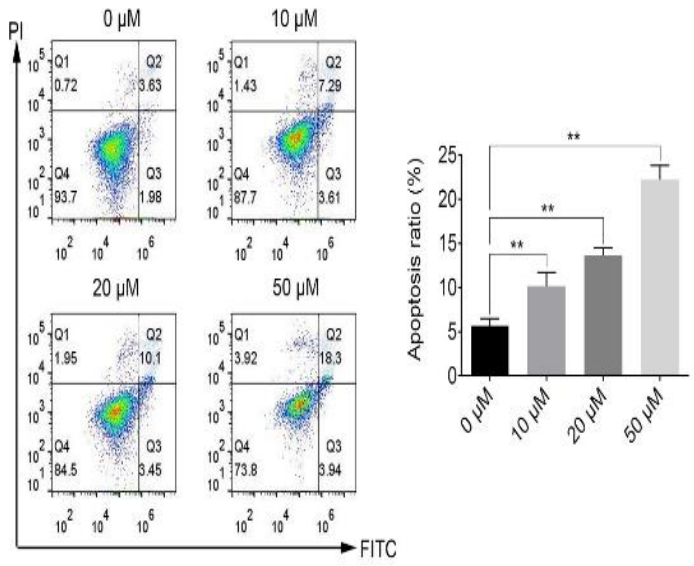

Figure 3: ISL promoted cell apoptosis in DLBCL cells in a concentration-dependent manner. ${ }^{* \star} P<0.01$ vs. 0 $\mu \mathrm{M}$ 


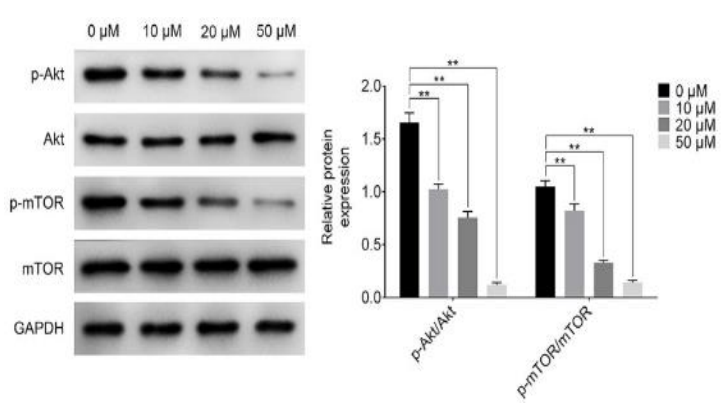

Figure 4: ISL repressed activation of the Akt/mTOR signaling pathway. Activation of the Akt/mTOR signaling pathway was reduced following ISL treatment in a concentration-dependent manner. ${ }^{* *} p<0.01$ vs. $0 \mu \mathrm{M}$

\section{DISCUSSION}

The biological activities of ISL are diverse. ISL is widely used in food additives and alternative medicine due to its various beneficial effects on disease prevention and in treatments, such as anti-microbial, anti-oxidative, cardioprotective, immunoregulatory, and anti-cancer effects [11]. Results from the present study indicate that in a DLBCL cell line, ISL reduced cell proliferation, induced cell apoptosis, and reduced cell cycle transition from $\mathrm{G} 1$ to $\mathrm{S}$ phase. The resulting cell cycle arrest in the $\mathrm{G} 1$ phase was mediated by inactivation of the Akt/mTOR signaling pathway, indicating the therapeutic possibility of ISL in the treatment of DLBCL.

The cell cycle is classically divided into four phases: G1 (pre-DNA synthesis), S (DNA synthesis), G2 (pre-division), and M (cell division) [16]. Dysregulation of the cell cycle is associated with many pathological process, including cancers [16]. In this study, cell proliferation was inhibited by ISL in a concentration-dependent manner, which was consistent with previous findings $[14,17]$. This indicates that ISL had an anti-cancer effect in the development and growth of DLBCL cells. Furthermore, flow cytometry results indicated that the inhibition of cell proliferation induced by ISL was mediated by suppression of cell cycle transition, inducing cell cycle arrest at the G1 phase. In the G1 phase, the formation of the cyclin D-cyclin-dependent kinase (CDK)4/6 complex regulates cell cycle progression from the $\mathrm{G} 1$ to $S$ phase [18], which may be the mechanism of ISL-induced apoptosis. However, further investigation is needed to determine whether there is an inhibitory effect of ISL on CDK4/6 activity.

The PI3K/Akt/mTOR signaling pathway is activated in the pathogenesis of cancers, including endometrial cancer, breast cancer, and
DLBCL [7]. In this study, phosphorylation of Akt and mTOR was measured in DLBCL cells following ISL treatment. The reduced levels of $p$ Akt and p-mTOR indicate that the Akt/mTOR signaling pathway was activated in DLBCL cells, which is consistent with previous studies $[19,20]$. Akt is a serine/threonine protein kinase that plays a key role in $\mathrm{PI} 3 \mathrm{~K}$ downstream signaling; phosphorylation of Akt is associated with cell proliferation and apoptosis [19,21].

In the present study, ISL reduced the phosphorylation of Akt in a concentrationdependent manner, indicating that inactivation of Akt following ISL treatment induced inhibition of cell proliferation and promotion of cell cycle arrest. As a main target of Akt, mTOR plays a critical role in cell-cycle progression from the $\mathrm{G}_{1}$ to $S$ phase [22]. Here, ISL reduced the phosphorylation of Akt in a concentrationdependent manner and the cell cycle was arrested at the G1 phase in cells treated with ISL, further confirming that ISL inhibited the survival of DLBCL cells through the regulation of the Akt/mTOR signaling pathway.

\section{CONCLUSION}

The findings of this study demonstrate that ISL prevents cell proliferation, induces apoptosis, and blocks cell cycle transition from the $\mathrm{G} 1$ to $\mathrm{S}$ phase, resulting in cell cycle arrest at $\mathrm{G} 1$ in a DLBCL cell line. These effects were mediated by inactivation of Akt/mTOR signaling pathway. Thus, ISL is a promising alternative medicinal agent for the management of patients suffering from DLBCL. However, large clinical trials are required prior to its use in clinical practice.

\section{DECLARATIONS}

\section{Conflict of interest}

No conflict of interest is associated with this work.

\section{Contribution of authors}

We declare that this work was done by the authors named in this article and all liabilities pertaining to claims relating to the content of this article will be borne by the authors. Zhixiang Su designed the study, supervised the data collection, and analyzed the data. Bin Yu interpreted the data and prepared the manuscript for publication. Zhiping Deng and Haifeng Sun supervised data collection and analyzed the data. All authors have read and approved the manuscript. 


\section{Open Access}

This is an Open Access article that uses a funding model which does not charge readers or their institutions for access and distributed under the terms of the Creative Commons Attribution License (http://creativecommons.org/licenses/by/ 4.0) and the Budapest Open Access Initiative (http://www.budapestopenaccessinitiative.org/rea d), which permit unrestricted use, distribution, and reproduction in any medium, provided the original work is properly credited.

\section{REFERENCES}

1. A clinical evaluation of the International Lymphoma Study Group classification of non-Hodgkin's lymphoma. The Non-Hodgkin's Lymphoma Classification Project. Blood 1997; 89(11): 3909-3918.

2. $\mathrm{Li} \mathrm{S}$, Young $\mathrm{KH}$, Medeiros LJ. Diffuse large B-cell lymphoma. Pathology 2018; 50(1): 74-87.

3. Jamil MO, Mehta A. Diffuse Large B-cell lymphoma: Prognostic markers and their impact on therapy. Expert Review of Hematology 2016; 9(5): 471-477.

4. Kubuschok B, Held G, Pfreundschuh M. Management of diffuse large B-cell lymphoma (DLBCL). Cancer Treat Res 2015; 165: 271-288.

5. Pfreundschuh $M$, Kuhnt $E$, Trümper L, Österborg $A$, Trneny M, Shepherd L, Gill DS, Walewski J, Pettengell $R$, Jaeger $U$ et al. CHOP-like chemotherapy with or without rituximab in young patients with good-prognosis diffuse large-B-cell lymphoma: 6-year results of an open-label randomised study of the MabThera International Trial (MInT) Group. The Lancet Oncology 2011; 12(11): 1013-1022.

6. Feugier $P$, Van Hoof $A$, Sebban $C$, Solal-Celigny $P$, Bouabdallah $R$, Fermé $C$, Christian $B$, Lepage E, Tilly $H$, Morschhauser $F$ et al. Long-Term Results of the $R$ CHOP Study in the Treatment of Elderly Patients With Diffuse Large B-Cell Lymphoma: A Study by the Groupe d'Etude des Lymphomes de l'Adulte. J Clin Oncol 2005; 23(18): 4117-4126.

7. Xia $P, X u X-Y$. PIJKJAkt/mTOR signaling pathway in cancer stem cells: from basic research to clinical application. American journal of cancer research 2015; 5(5): 1602-1609.

8. Zhang $Y$, Sun X, Icli B, Feinberg MW. Emerging Roles for MicroRNAs in Diabetic Microvascular Disease: Novel Targets for Therapy. Endocrine Reviews 2017; 38(2): 145-168.

9. Majchrzak A, Witkowska $M$, Smolewski $P$. Inhibition of the PI3K/Akt/mTOR signaling pathway in diffuse large $B$-cell lymphoma: current knowledge and clinical significance. Molecules (Basel, Switzerland) 2014; 19(9): 14304-14315.

10. Nie L, Zhang L. Gastric cancer cell proliferation is inhibited by \&alpha-santonin via targeting of PI3K and AKT activation. Trop J Pharm Res 2020; 19(4): 765-771.

11. Peng $F, D u Q$, Peng C, Wang N, Tang H, Xie X, Shen J, Chen J. A Review: The Pharmacology of Isoliquiritigenin. Phytotherapy Research 2015; 29(7): 969-977.

12. Zhang L, Ma S, Su H, Cheng J. Isoliquiritigenin Inhibits IL-1 $\beta$-Induced Production of Matrix Metalloproteinase in Articular Chondrocytes. Molecular therapy Methods \& clinical development 2018; 9: 153-159.

13. Chen $X$, Cai $X$, Le $R$, Zhang M, Gu X, Shen F, Hong G, Chen $Z$. Isoliquiritigenin protects against sepsis-induced lung and liver injury by reducing inflammatory responses. Biochem Biophys Res Commun 2018; 496(2): 245-252.

14. Zhang B, Lai $Y$, Li $Y$, Shu $N$, Wang Z, Wang $Y, L i Y$, Chen Z. Antineoplastic activity of isoliquiritigenin, a chalcone compound, in androgen-independent human prostate cancer cells linked to G2/M cell cycle arrest and cell apoptosis. Eur J Pharmacol 2018; 821: 57-67.

15. Tian T, Sun J, Wang J, Liu Y, Liu H. Isoliquiritigenin inhibits cell proliferation and migration through the PI3KJAKT signaling pathway in A549 lung cancer cells. Oncol Lett 2018; 16(5): 6133-6139.

16. Hamilton E, Infante JR. Targeting CDK4/6 in patients with cancer. Cancer Treatment Reviews 2016; 45: 129-138.

17. Wang TT, Chen ZZ, Xie P, Zhang WJ, Du MY, Liu YT, Zhu HY, Guo YS. Isoliquiritigenin suppresses the proliferation and induced apoptosis via miR32/LATS2/Wnt in nasopharyngeal carcinoma. Eur $J$ Pharmacol 2019; 856; 172352.

18. O'Leary B, Finn RS, Turner NC. Treating cancer with selective CDK4/6 inhibitors. Nature Reviews Clinical Oncology 2016; 13(7): 417-430.

19. Xu ZZ, Xia ZG, Wang AH, Wang WF, Liu ZY, Chen LY, Li JM. Activation of the PISKJAKT/mTOR pathway in diffuse large $B$ cell lymphoma: clinical significance and inhibitory effect of rituximab. Ann Hematol 2013; 92(10): 1351-1358.

20. Ezell SA, Wang S, Bihani T, Lai Z, Grosskurth SE, Tepsuporn S, Davies BR, Huszar D, Byth KF. Differential regulation of $m T O R$ signaling determines sensitivity to $A K T$ inhibition in diffuse large $B$ cell lymphoma. Oncotarget 2016; 7(8): 9163-9174.

21. Zhai $H$, Kang Z, Zhang $H$, Ma J, Chen G. Baicalin attenuated substantia nigra neuronal apoptosis in Parkinson's disease rats via the mTOR/AKT/GSK-3 $\beta$ pathway. J Integr Neurosci 2019; 18(4): 423-429.

22. Morgensztern D, McLeod HL. PI3K/Akt/mTOR pathway as a target for cancer therapy. Anti-Cancer Drugs 2005; 16(8). 